\title{
Reference equations for pulmonary diffusing capacity of carbon monoxide and nitric oxide in adult Caucasians
}

\author{
Mathias Munkholm ${ }^{1}$, Jacob Louis Marott ${ }^{2}$, Lars Bjerre-Kristensen ${ }^{3}$, \\ Flemming Madsen ${ }^{4}$, Ole Find Pedersen ${ }^{5}$, Peter Lange ${ }^{2,6,7}$, \\ Børge G. Nordestgaard ${ }^{6,8}$ and Jann Mortensen ${ }^{1,9}$
}

Affiliations: ${ }^{1}$ Dept of Clinical Physiology, Nuclear Medicine and PET, Rigshospitalet, Copenhagen University Hospital, Copenhagen, Denmark. ${ }^{2}$ The Copenhagen City Heart Study, Frederiksberg Hospital, Copenhagen, Denmark. ${ }^{3}$ Dept of Respiratory Diseases, Aarhus University Hospital, Aarhus, Denmark. ${ }^{4}$ Danish Lung Function Laboratory, Copenhagen, Denmark. ${ }^{5}$ Department of Public Health at University of Aarhus, Aarhus, Denmark. ${ }^{6}$ The Copenhagen General Population Study, Herlev Hospital, Copenhagen University Hospital, University of Copenhagen, Copenhagen, Denmark. ${ }^{7}$ Dept of Social Medicine, Institute of Public Health, University of Copenhagen, Copenhagen, Denmark. ${ }^{8}$ Dept of Clinical Biochemistry, Herlev Hospital, Copenhagen University, Hospital, University of Copenhagen, Copenhagen, Denmark. ${ }^{9}$ Dept of Medicine, The Faroese National Hospital, Torshavn, Faroe Islands.

Correspondence: Jann Mortensen, Dept of Clinical Physiology, Nuclear Medicine and PET, Rigshospitalet, DK-2100 Copenhagen, Denmark. E-mail: jann.mortensenaregionh.dk

@ERSpublications

Reference equations for the DLCONO measurement based on state-of-the-art methodology http://ow.ly/6VqD30khPEp

Cite this article as: Munkholm M, Marott JL, Bjerre-Kristensen L, et al. Reference equations for pulmonary diffusing capacity of carbon monoxide and nitric oxide in adult Caucasians. Eur Respir J 2018; 52: 1500677 [https://doi.org/10.1183/13993003.00677-2015].

ABSTRACT The aim of this study was to determine reference equations for the combined measurement of diffusing capacity of the lung for carbon monoxide (CO) and nitric oxide (NO) (DLCONO). In addition, we wanted to appeal for consensus regarding methodology of the measurement including calculation of diffusing capacity of the alveolo-capillary membrane $(D \mathrm{~m})$ and pulmonary capillary volume $\left(V_{c}\right)$.

DLCONO was measured in 282 healthy individuals aged 18-97 years using the single-breath technique and a breath-hold time of $5 \mathrm{~s}$ (true apnoea period). The following values were used: 1) specific conductance of nitric oxide $\left.(\theta \mathrm{NO})=4.5 \mathrm{mLNO} \cdot \mathrm{mLblood}{ }^{-1} \cdot \mathrm{min}^{-1} \cdot \mathrm{mmHg}^{-1} ; 2\right)$ ratio of diffusing capacity of the membrane for $\mathrm{NO}$ and $\mathrm{CO}(\mathrm{DmNO} / \mathrm{DmCO})=1.97$; and 3$) 1 /$ red cell CO conductance $(1 / \theta \mathrm{CO})=(1.30$ $+0.0041 \cdot$ mean capillary oxygen pressure $) \cdot\left(14.6 / \mathrm{Hb}\right.$ concentration in $\left.\mathrm{g} \cdot \mathrm{dL}^{-1}\right)$.

Reference equations were established for the outcomes of DLCONO, including DLCO and DLNO and the calculated values $D \mathrm{~m}$ and $V_{c}$. Independent variables were age, sex, height and age squared.

By providing new reference equations and by appealing for consensus regarding the methodology, we hope to provide a basis for future studies and clinical use of this novel and interesting method. 


\section{Introduction}

Marie KROGH [1] developed a method for measuring pulmonary gas exchange in Copenhagen a century ago. Since then, measurement of diffusing capacity of the lung for carbon monoxide (DLCO) has been used in both work-up and monitoring of a wide variety of pulmonary disorders. Since the work of RoUGHTON and Forster [2] in 1957, the model for transfer of a gas from alveolus to blood has been described as consisting of two resistances in series:

$$
1 / D \mathrm{~L}=1 / D \mathrm{~m}+1 /\left(\theta \mathrm{b} \cdot V_{\mathrm{c}}\right)
$$

where $1 / D \mathrm{~L}$ is the total resistance for the specific gas in min.mmHg.mLgas ${ }^{-1}, 1 / D \mathrm{~m}$ is the resistance to passive diffusion through the alveolocapillary membrane and $1 /\left(-b \cdot V_{c}\right)$ represents the resistance of gas uptake of the blood. $D \mathrm{~m}$ is the membrane conductance for a given gas (in $\mathrm{mLgas} \cdot \mathrm{min}^{-1} \cdot \mathrm{mmHg}^{-1}$ ), $\theta \mathrm{b}$ (blood conductance) is the amount of gas taken up by the blood per $\mathrm{mmHg}$ tension (in $\mathrm{mLgas} \cdot \mathrm{mLblood}^{-1} \cdot \mathrm{min}^{-1} \cdot \mathrm{mmHg}^{-1}$ ) and $V_{\mathrm{c}}$ is the pulmonary capillary blood volume (in $\mathrm{mL}$ ).

Using carbon monoxide (CO) as the inhaled gas, Roughton and Forster showed how to determine values for $D \mathrm{~m}$ and $V_{\mathrm{c}}$ by solving the above equation with two unknown variables. The method required measurements of DLCO at two or more different oxygen $\left(\mathrm{O}_{2}\right)$ tensions, since an increase in inhaled $\mathrm{O}_{2}$ tension results in a decrease in $\theta$ CO and thereby a decrease in the measured DLCO [2]. In 1987, GuENARD et al. [3] proposed an alternative way of determining $D \mathrm{~m}$ and $V_{\mathrm{c}}$, using $\mathrm{CO}$ and nitric oxide (NO) in one combined single-breath manoeuvre (DLCONO), making measurements considerably more convenient and possibly also more precise and thereby more suitable for use in clinical work [4]. Using this test, as opposed to the standard DLCO measurement, clinicians will obtain more detailed information about the pathoanatomy/pathophysiology underlying a low diffusion capacity, for example, if the defect is related primarily to $D \mathrm{~m}$ or $V_{\mathrm{c}}$.

In the work of GUENARD et al. [3], ONO was assumed to be infinitely great, since it had been shown earlier that the reaction rate of $\mathrm{NO}$ with free haemoglobin $(\mathrm{Hb})$ was 250-1400 times faster than for $\mathrm{CO}[2,3,5,6]$. However, in recent years the correctness of this assumption has been thoroughly debated and recent evidence points towards $\theta$ NO being finite, with a value of $4.5 \mathrm{mLNO} \cdot \mathrm{mLblood}^{-1} \cdot \mathrm{min}^{-1} \cdot \mathrm{mmHg}^{-1}[7-10]$. This value is used in the present study.

Other disputed issues in this area of research are the true value of $\theta$ CO and the value of $\alpha=D \mathrm{mNO} / D \mathrm{mCO}$. In the present study, Fonster's [11] 1987 values for $\theta \mathrm{CO}$ measured at $\mathrm{pH} 7.4$ are used together with $\alpha=1.97$. The considerations underlying these choices are presented in the discussion.

To date, a small number of reference values for the DLCONO method have been published, but most of these include a rather limited number of subjects $(n=10-71)$ [6]. However, one study included 124 healthy adults with a mean \pm SD age of $\sim 40 \pm 12$ years) [12] and another study population comprised 130 subjects, of which only 17 were aged $>60$ years [13]. Furthermore, one larger study from 2008 includes 303 healthy adults aged 20-80 years and had a more uniform age distribution [14]. Recently, ZAVORSKY et al. [15] combined and reanalysed data from these three studies in order to achieve one combined set of reference equations. This procedure has the obvious benefit of reference values relying on a greater number of subjects, but considering a rather wide spectrum in the mean values between these studies, differences in methodology, e.g. breath-hold time, and the limited amount of data obtained from healthy people aged $>60$ years, there still is an obvious need for an additional larger study to reliably establish reference values for this new test before it can be used in the daily clinical work-up of patients.

Based on state-of-the-art methodology, the aim of this study is to establish new reference values for the DLCONO measurement. In that respect, we also wish to achieve consensus regarding methodology of the measurement including calculation of $D \mathrm{~m}$ and $V \mathrm{c}$, so that these values can be of clinical use in the future.

\section{Methods}

Subjects

A sample of 282 healthy adults aged 18-97 years was recruited between September 11, 2013 and June 18, 2014. They were randomly chosen from the Copenhagen General Population Study, a large general population cohort study including $>100000$ participants aged $\geqslant 20$ years who had been randomly selected from the Danish Civil Registration System. Details about this study have been published previously [16, 17]. In addition, participants aged 18-20 years were randomly selected from the Danish Civil Registration System. Subjects were selected in order to achieve a uniform age distribution. Inclusion criteria were age $\geqslant 18$ years, both parents of European origin, nonsmoker or former use of tobacco $<1$ pack-year, no known pulmonary or cardiovascular disease, no acute respiratory symptoms 4 weeks prior to investigation, no prior operation or radiation therapy of the chest, body mass index (BMI) $<30 \mathrm{~kg} \cdot \mathrm{m}^{-2}$ and no pregnancy. 
The subjects lived in Copenhagen or the surrounding area and comprised a socioeconomically heterogeneous group.

\section{Ethics}

All participants received written and verbal information about the study and gave their informed consent. The Danish Data Protection Agency and a Danish committee on health research ethics approved the study.

\section{Measurement of diffusing capacities for $\mathrm{CO}$ and NO}

Measurements of DLCO and DLNO were achieved simultaneously during a single-breath manoeuvre using Jaeger Masterscreen PFT pro (CareFusion, Hoechberg, Germany). Two identical sets of equipment were used. Before measurement of diffusing capacity, standing height (to nearest $1 \mathrm{~mm}$ ), weight (to nearest $100 \mathrm{~g}$ ) and $\mathrm{Hb}$ (to nearest $0.1 \mathrm{mmol} \cdot \mathrm{L}^{-1}$ ) of the participants were obtained. $\mathrm{Hb}$ was measured from capillary blood using HemoCue $\mathrm{Hb}^{\varpi} 201+$ (HemoCue, Brønshøj, Denmark). It has been shown that $\mathrm{Hb}$ measured from a capillary blood sample closely resembles $\mathrm{Hb}$ measured from a venous blood sample taken from the vein of a forearm [18]. In addition, spirometry, body plethysmography and standard single-breath DLCO were performed in all subjects. Measurements were taken at $20 \mathrm{~m}$ above sea level. The DLCONo test was performed as follows. After a minimum of $30 \mathrm{~min}$ without any form of straining physical activity participants sat down, were equipped with a nose clip, and, after automatic resetting of the device, started tidal breathing through a mouthpiece and filter (SpiroBac; Henrotech, Aartselaar, Belgium) (dead space $56 \mathrm{~mL}$, resistance to flow at $12 \mathrm{~L} \cdot \mathrm{s}^{-1} 0.9 \mathrm{cmH}_{2} \mathrm{O}$ ) connected to the pneumotach. After completing a few tidal breaths, subjects were requested to perform a full expiration followed by a rapid full inspiration during which a valve opened allowing them to inspire the test gases. Following that, a breath-hold of $5 \mathrm{~s}$ was performed (true apnoea period). The actual breath-hold time was calculated using the JonEs and MEADE [19] method and was found to be mean \pm SD $6 \pm 0.44 \mathrm{~s}$. The participants then performed a fast expiration, and after a $V_{\text {washout }}=0.6 \mathrm{~L}$, a $V_{\text {sample }}=0.6 \mathrm{~L}$ was collected. The procedure was repeated after a 4-min wait. The measurements were considered acceptable if the difference between the two measurements of DLCO was $<10 \%$ or $<3 \mathrm{~mL} \cdot \mathrm{min}^{-1} \cdot \mathrm{mmHg}^{-1}$, as recommended by American Thoracic Society (ATS)/ European Respiratory Society (ERS) guidelines [20]. If this was not the case, additional measurements (up to five in total) were performed, until the difference between the highest and second highest measurement of DLCO met the requirements. In the vast majority of tests, the repeatability criteria were obtained after only two measurements. From the two chosen measurements, mean values for DLCO, DLNO, diffusion capacity per unit alveolar volume for $\mathrm{CO}(\mathrm{KCO})$ and for $\mathrm{NO}(\mathrm{KNO})$ and $V \mathrm{~A}$ (alveolar volume) were calculated. The gas used for the measurements consisted of $0.28 \% \mathrm{CO}, 9.3 \%$ helium (He), 20.9\% $\mathrm{O}_{2}$ and $69.52 \%$ nitrogen $\left(\mathrm{N}_{2}\right)$ (analysis uncertainty $\pm 2.0 \%$ relative) (Linde Healthcare/AGA, Copenhagen, Denmark), which was mixed with $400 \mathrm{ppm} \mathrm{NO} / \mathrm{N}_{2}$ (analysis uncertainty $\pm 5.0 \%$ relative) (Linde Healthcare/AGA) in an inspiratory bag just before inhalation. The resulting inspired concentrations are presented in table 1 . Due to a procedure where the system was flushed with $100 \% \mathrm{O}_{2}$ to empty any tubes that might contain $\mathrm{CO} / \mathrm{He} / \mathrm{NO}$ gas, the $\mathrm{O}_{2}$ concentration was higher in the inspiratory bag than in the initial gas tank. The inert gas, $\mathrm{He}$, was used in the calculation of $V A$ by means of the He-dilution technique.

In our calculations we did not account for NO backpressure, since concentrations of endogenous exhaled $\mathrm{NO}$ at rest range between 11 and $66 \mathrm{ppb}$ and therefore were considered negligible compared to our NO measurements, which were in the ppm range [21, 22]. In addition, ZAVORSKY [23] showed that up to 22

TABLE 1 Summary of methodology for the two diffusion capacity methods

\section{DLCONo method}

\section{5}

$0.19 \pm 0.018 \% \mathrm{CO}, 6.34 \pm 0.59 \% \mathrm{He}, 22.36 \pm 0.71 \%$ $\mathrm{O}_{2}, 52 \pm 6 \mathrm{ppm} \mathrm{NO}$, balance $\mathrm{N}_{2}$

$\mathrm{He}$

NO: CiTicel" 7BNT electrochemical cell, CO: electrochemical cell, $\mathrm{He}$ : thermal conductivity, $\mathrm{O}_{2}$ : electrochemical cell

Physical sample from collection bag

\section{DLco method}

\section{0}

$0.3 \% \mathrm{CO}, 0.3 \% \mathrm{CH}_{4}, 20.9 \%$

$\mathrm{O}_{2}$, balance $\mathrm{N}_{2}$

$\mathrm{CH}_{4}$

$\mathrm{CO}, \mathrm{CH}_{4}$ : nondispersive infrared thermopile

Virtual sample constructed from signals from flow and gas concentration

DLCONO: combined diffusing capacity of the lung for carbon monoxide and nitric oxide; $D$ LCO: diffusing capacity of the lung for carbon monoxide; CO: carbon monoxide; He: helium; $\mathrm{O}_{2}$ : oxygen; $\mathrm{NO}$ : nitric oxide; $\mathrm{N}_{2}$ : nitrogen; $\mathrm{CH}_{4}$ : methane. ${ }^{\#}$ : true apnoea period; ${ }^{\text {? }}$ : CiTicel, City Technology, Nuremberg, Germany. 
repetitions of the DLCONO measurement does not lead to a decrease in DLNO values. Likewise, he showed that up to 12 repetitions of the test could be performed without significantly lowering DLCO values. Therefore, potential accumulation of $\mathrm{CO}$ in the blood creating $\mathrm{CO}$ backpressure and thereby decreasing DLCO measurements were not considered to be a problem in the present study.

In addition, we performed the standard DLCO measurement on all subjects. Apart from the methodological differences presented in table 1, the two procedures were performed in the same way.

In order to be able to differentiate between the two methods, outcomes from the DLCONO measurement are denoted with " $5 \mathrm{~s}$ " and outcomes from the standard DLCO measurement with "10s", e.g. VA10s for VA measured using the standard DLCO method.

\section{Quality control}

The quality and reproducibility of the measurements were ensured by the following means. Each day the pneumotach was calibrated using the three-flow method with a calibrated 3-L syringe and the apparatus was calibrated for gas fractions using automated procedures for $\mathrm{He}, \mathrm{CO}, \mathrm{O}_{2}$ and methane $\left(\mathrm{CH}_{4}\right)$. Furthermore, the linearity of the analysers was factory checked. In addition, by using three gases, with different concentrations of $\mathrm{CO}$ and NO, linearity was checked before start of the study, in the middle of the study and at its end. Moreover, biological control measurements, in which the same subject performed DLCONO measurements on both pieces of equipment in order to detect fluctuations in values, were performed regularly and showed high levels of repeatability. Furthermore, accuracy of the VA measurements was checked before start of the study, in the middle of the study and at its end. To our knowledge, no technique has been developed to check VA obtained during the DLCONO measurements. Therefore, the correctness of the VA measurements pertaining to the standard DLCO technique with $\mathrm{CH}_{4}$ as the inert gas was checked both using the Hans Rudolph (Shawnee, KS, USA) DLCO Simulator with EasyLab $^{\text {TM }}$ software [24] and using the JQM-syringe DLCO test, in which a DLCO test is performed using a 3-L calibration syringe. Important differences to a normal DLCO test is the fact that the pneumotach is non-heated and that no corrections are made for carbon dioxide or ambient temperature and pressure, saturated with water vapour/body temperature, ambient pressure, saturated with water vapour. VA measurements obtained using the DLCO technique could later be compared with VA measurements pertaining to the DLCONO technique.

Both sets of equipment passed all the tests performed.

Calculation of $\mathrm{Dm}, 1 / \theta \mathrm{co}$ and $\mathrm{V}_{c}$

As mentioned, we took as our starting point the formula proposed by RoUGHTON and FORSTER [2]:

$$
1 / D \mathrm{~L}=1 / D \mathrm{~m}+1 /\left(\theta \mathrm{b} \cdot V_{\mathrm{c}}\right)
$$

According to the most recent knowledge, $\theta \mathrm{NO}$ is considered to be finite with a value of $4.5 \mathrm{mLNO} \cdot \mathrm{mLblood}^{-1} \cdot \mathrm{min}^{-1} \cdot \mathrm{mmHg}^{-1}$. Thereby the calculation of DmCO is as follows:

$$
D \operatorname{mCO}=(1 / \alpha-1 / \mathrm{k}) /(1 / D \mathrm{LNO}-1 /(\mathrm{k} \cdot \mathrm{DLCO}))
$$

Where $\alpha=D \mathrm{mNO} / D \mathrm{mCO}=1.97$ and $\mathrm{k}=\theta \mathrm{NO} / \theta \mathrm{CO}$. It is important to realise that $\mathrm{k}$ is not a constant, since it changes with changes in $\mathrm{Hb}$ concentration and mean capillary oxygen pressure $\left(P_{\mathrm{capO}_{2}}\right)[3,10,25]$.

When calculating 1/ӨCO, Forster's [11] 1987 values for $\theta$ CO measured at pH 7.4 were used:

$$
1 / \theta \mathrm{CO}=\left(1.30+0.0041 \cdot \mathrm{PcapO}_{2}\right) \cdot\left(14.6 / \mathrm{Hb} \text { concentration in } \mathrm{g} \cdot \mathrm{dL}^{-1}\right)
$$

Most earlier publications in the field have used $P_{c a p O}=100 \mathrm{mmHg}$. However, in the present study, the inspiratory fraction of $\mathrm{O}_{2}$ was higher than in these studies due to the flushing procedure already described. In order to be able to compare our results with earlier results, we did a correction for $\mathrm{O}_{2}$ as follows.

Presuming $P_{\mathrm{capO}_{2}}=100 \mathrm{mmHg}$, at standard $\mathrm{Hb}$ concentrations (males $14.6 \mathrm{~g} \cdot \mathrm{dL}^{-1}$, females $13.4 \mathrm{~g} \cdot \mathrm{dL}^{-1}$ ) [20], this provides the following values for $1 / \theta \mathrm{CO}$ : males $1.710 \mathrm{mLblood} \cdot \mathrm{min} \cdot \mathrm{mmHg} \cdot \mathrm{mLCO}^{-1}$, females $1.863 \mathrm{mLblood} \cdot \mathrm{min} \cdot \mathrm{mmHg} \cdot \mathrm{mLCO}^{-1}$ 
$V_{\mathrm{c}}$ was calculated using the following formula:

$$
V \mathrm{c}=(1 / \theta \mathrm{CO})(1-\alpha / \mathrm{k}) /(1 / \mathrm{DLCO}-\alpha / D \mathrm{LNO})
$$

Again, $\alpha=D \mathrm{mNO} / D \mathrm{mCO}=1.97$ and $\mathrm{k}=\theta \mathrm{NO} / \theta \mathrm{CO}$.

As mentioned, the choices made in reference to these calculations are considered in more detail in the Discussion.

Correction for $\mathrm{O}_{2}$

Largely, the $\mathrm{O}_{2}$ correction was performed as described by MArTinot et al. [10]. First, $\mathrm{PcapO}_{2}$ was calculated using the following equation:

$$
\mathrm{PAO}_{2}-\mathrm{PcapO}_{2}=\mathrm{VO}_{2} / \mathrm{DLO}_{2}
$$

Where $\mathrm{PAO}_{2}$ was the alveolar oxygen tension measured in the expired sample and $V^{\prime} \mathrm{O}_{2}$ was the oxygen uptake calculated from the mass balance of oxygen between inspiration and expiration in the manoeuvre. The oxygen fraction measured in the sample volume (mid-expiratory) was assumed to be similar to the oxygen fraction in the residual volume at end-expiration. The diffusion capacity of the lung for oxygen $\left(D \mathrm{LO}_{2}\right)$ was assumed to be equal to $D \mathrm{LCO} 5 \mathrm{~s} \times 1.23$.

For each subject we then calculated the $1 / \theta \mathrm{CO}$ value corresponding to their $\mathrm{P}_{\mathrm{capO}}$ value and standard $\mathrm{Hb}$. This $1 / \theta$ CO value was used to calculate $D \mathrm{mCO}$ and $V_{\mathrm{c}}$ in the high $\mathrm{O}_{2}$ conditions described. Finally, $1 / \theta \mathrm{CO}$ corresponding to $P_{\mathrm{CapO}_{2}}=100 \mathrm{mmHg}$ and standard $\mathrm{Hb}$ was calculated, and by rearranging the RouGHTON and Forster equation, this value and the calculated values of $D$ mCO5s and $V_{c}$ were used to calculate DLCO corresponding to $P_{\mathrm{CaPO}_{2}}=100 \mathrm{mmHg}$. Thereby, these DLCO5s values were uncorrected for $\mathrm{Hb}$.

\section{Correction for $\mathrm{Hb}$}

$\mathrm{Hb}$-corrected values for $\mathrm{DmCO}$ and $V_{\mathrm{c}}$ (labelled "Hb-corr") were found by calculating the 1/0CO value corresponding to the $P_{\mathrm{capO}}$ value and measured $\mathrm{Hb}$ of each subject. This $1 / \theta \mathrm{cOHb}$-corr value was then used to calculate $D \mathrm{mCOHb}$-corr and $V_{\mathrm{cHb}}$-corr, as already described. $\mathrm{Dm}$ is regarded as being independent of $\mathrm{Hb}$, but when estimating $D \mathrm{~m}$ from the DLCONO measurement, $\mathrm{Hb}$ is to be taken into account since the calculation of $D$ m includes DLCO, which is dependent on Hb. In order to determine DLCO5sHb-corr, 1/0CO corresponding to $\mathrm{P}_{\mathrm{capO}}=100 \mathrm{mmHg}$ and standard $\mathrm{Hb}$ was calculated, and by rearranging the RouGHTON and FORSTER equation, this value and the calculated values of $\mathrm{DmCOHb}$-corr and $V_{\mathrm{cHb}}$-corr were used to calculate DLCO5s Hb-corr corresponding to $\mathrm{P}_{\mathrm{CapO}_{2}}=100 \mathrm{mmHg}$.

\section{Statistical analyses}

For demographics, ANOVA was applied to compare means of continuous variables.

Reference equations were established using stepwise model selection in multiple linear regression analysis according to the Akaike information criterion. Possible explanatory variables were age, age squared, sex and height. For equations in table 3, data were stratified by sex. The stepwise regression analysis was initially performed on the entire dataset. Second, data screening was conducted in two steps and based on the initial models. In step 1 of the data screening, cases with residuals $\geqslant 3.0 \mathrm{SD}$ units above and below the predicted values (individual models for each outcome) were removed. In step 2, the same exclusion criterion was used in the regression analysis based on the reduced datasets. Note that an excluded case for one outcome can be included for the other outcomes. Finally, the stepwise regression analysis was performed on data without outliers. The model selection was unaffected by the data screening, since the initial model selection resulted in the exact same models as the model selection based on data without outliers.

To compare the outcomes according to different breath-hold times, Passing-Bablok regression analyses were performed. 95\% confidence intervals were calculated using quantile nested bootstrap resampling.

The residual standard deviation (RSD) expresses the variation from the reference equation, and the predicted value $\pm 1.96 \times \mathrm{RSD}$ approximates the 2.5 th and 97.5 th percentiles.

The plots of the reference equations were stratified by sex and present predicted values according to median height. The median height was based on quantile regression with age as explanatory variable.

All analyses were performed using the statistical software R (version 3.2.0; R Foundation, www.r-project.org). 


\section{Results}

Baseline characteristics of the study population are presented in table 2 . When expressed as $\%$ predicted values [26], we found no statistically significant difference in forced expiratory volume in $1 \mathrm{~s}$ (FEV1), forced vital capacity (FVC) or FEV1/FVC ratio between females and males.

The age distribution of the study population is presented in figure 1 . As seen, the age distribution was close to uniform and decreased only slightly for ages $>85$ years.

Reference equations for the DLCONO measurement are presented in table 3. As seen, after stratification by sex, the independent variables were height, age and age squared, although not all independent variables were included in all equations. The introduction of age squared allows for an accelerated decrease in the dependent variable with increasing age (figure $2 \mathrm{a}$ and $\mathrm{b}$ ).

The DLNO/DLCO5s ratio \pm SD was found to be $4.4 \pm 0.24$ and was only marginally dependent on age and height (the latter relationship being nonsignificant). Linear regression analysis with age and height as the only variables showed $\mathrm{p}=0.00032$ with a slope of -0.00251 for age and $\mathrm{p}=0.058$ with a slope of -0.00284 for height (in $\mathrm{cm}$ ). Adjusted $\mathrm{r}^{2}=0.0403$ (after data screening).

The reference equations for DLCO5s and DLNO were compared to previously published reference equations for adults (figure $2 \mathrm{a}$ and $\mathrm{b}$ ).

In addition, using Pearson's $\mathrm{r}$ and Passing-Bablok regression we compared DLCO, KCO and VA from the DLCONO and standard DLCO methods, respectively (figure 3a-c). As expected, in all three cases 10-s and 5-s values were strongly correlated with Pearson's $r>0.9$. However, when using Passing-Bablok regression the 10-s and 5-s methods were shown to be slightly different from each other, since 1 was not included in the 95\% confidence interval for slope in any of the three cases. For VA, Passing-Bablok regression showed that VA10s was systematically higher than VA5s by a constant of 0.01 , and proportionally higher by a factor of 1.04 . In addition, we found VA10s to be significantly higher with the mean \pm SD of the difference being $0.28 \pm 0.25 \mathrm{~L}(\mathrm{p}<0.01)$.

The mean red cell fraction of the total resistance for $\mathrm{CO}$ uptake, that is the fraction that $1 /\left(\theta \mathrm{CO} \cdot V_{\mathrm{c}}\right)$ constitutes of the total resistance $1 / D$ LCO, was found to be $72.3 \%$. For NO, the corresponding value $((1 /$ $\left.\left.\left(\theta \mathrm{NO} \cdot V_{\mathrm{c}}\right)\right) /(1 / \mathrm{DLNO})\right)$ was $39.3 \%$

\section{TABLE 2 Characteristics of the study population}

\begin{tabular}{|c|c|c|}
\hline & Females & Males \\
\hline Subjects $\mathrm{n}$ & 142 & 140 \\
\hline Age years & $53.4 \pm 22.6(18-97)^{\pi}$ & $54.1 \pm 22.3(18-97)$ \\
\hline Height cm & $165.4 \pm 7.2(148.8-183.8)^{* *}$ & $179.4 \pm 8.1(155.6-197.5)$ \\
\hline Weight kg & $64.6 \pm 9.0(45.1-97.0)^{* *}$ & $78.5 \pm 11.0(52.0-108.8)$ \\
\hline $\mathrm{BMI} \mathrm{kg} \cdot \mathrm{m}^{2}$ & $23.6 \pm 2.7(18.1-29.8)^{9}$ & $24.4 \pm 2.6(18.0-30.0)$ \\
\hline $\mathrm{Hb} g \cdot \mathrm{dL}^{-1}$ & $13.26 \pm 1.13(10.47-15.95)^{* *}$ & $14.62 \pm 1.36(11.28-19.01)$ \\
\hline FEV 1 L & $3.00 \pm 0.79(1.22-4.66)^{* *}$ & $4.08 \pm 1.02(1.43-6.31)$ \\
\hline FEV $1 \%$ pred [26] & $114.6 \pm 21.7(80.9-235.2)^{9}$ & $109.6 \pm 16.7(68.8-166.9)$ \\
\hline FEV1 Z-score & $0.9 \pm 1.0(-1.6-3.7)^{9}$ & $0.6 \pm 1.1(-2.4-3.7)$ \\
\hline FVC L & $3.76 \pm 0.86(1.91-5.83)^{* *}$ & $5.24 \pm 1.22(1.96-8.50)$ \\
\hline FVC $\%$ pred [26] & $113.1 \pm 17.3(84.5-197.4)^{\pi}$ & $111.0 \pm 14.9(78.8-171.5)$ \\
\hline FVC Z-score & $0.84 \pm 0.99(-1.32-3.30)^{\pi}$ & $0.79 \pm 1.05(-1.67-3.77)$ \\
\hline FEV1/FVC \% [26] & $79.2 \pm 7.1(60.7-95.7)^{\pi}$ & $77.8 \pm 7.3(55.4-98.8)$ \\
\hline FEV1/FVC Z-score & $0.0 \pm 1.0(-2.7-2.3)^{\pi}$ & $-0.3 \pm 1.2(-3.8-3.9)$ \\
\hline$V$ A5s L & $4.8 \pm 0.7(3.1-7.5)^{* *}$ & $6.4 \pm 1.1(3.4-8.6)$ \\
\hline VA5s \% pred [27] & $102.7 \pm 12.5(74.7-135.0)^{* *}$ & $96.2 \pm 11.9(65.3-121.8)$ \\
\hline DLco10s $\mathrm{mL} \cdot \mathrm{min}-{ }^{1} \cdot \mathrm{mmHg}^{1}$ & $22.1 \pm 5.1(10.1-34.6)^{* *}$ & $30.5 \pm 7.8(11.4-46.1)$ \\
\hline DLco10s \% pred [28] & $90.1 \pm 12.0(59.7-120.1)^{* *}$ & $98.2 \pm 14.3(60.3-150.6)$ \\
\hline TLC $^{\#} \mathrm{~L}$ & $5.5 \pm 0.8(3.8-8.0)^{* *}$ & $7.5 \pm 1.1(4.2-10.1)$ \\
\hline TLC $\#$ \% pred [29] & $106.5 \pm 11.7(77.4-136.2)^{* *}$ & $102.9 \pm 10.8(78.8-129.4)$ \\
\hline \multicolumn{3}{|c|}{$\begin{array}{l}\text { Data are presented as mean } \pm \text { SD (range), unless otherwise stated. Range: lowest to highest value; BMI: body } \\
\text { mass index; Hb: haemoglobin; FEV } 1 \text { : forced expiratory volume in } 1 \mathrm{~s} ; \% \text { pred: } \% \text { predicted; FVC: forced vital } \\
\text { capacity; VA5s: alveolar volume (from the DLCoNo (combined diffusing capacity of the lung for carbon } \\
\text { monoxide and nitric oxide) method); DLC010s: diffusing capacity of the lung for carbon monoxide (from the } \\
\text { standard } 10-\mathrm{s} \text { method); TLC: total lung capacity (from body plethysmography). }{ }^{\#}: 1 \text { female and } 1 \text { male } \\
\text { were excluded from the TLC calculations because they did not undergo the body plethysmography } \\
\text { measurement; }{ }^{\text {": }} \text { nonsignificant; }{ }^{* *}: p<0.01 \text {. }\end{array}$} \\
\hline
\end{tabular}


In order to examine sex differences in lung structure, regressions were performed for $V_{\mathrm{c}} / V_{\mathrm{A}} 5 \mathrm{~s}$ and $D_{\mathrm{mCO}} /$ VA5s (table 4). Both of these ratios were affected by sex, but in opposite directions. That is, $V_{c} / V_{A} 5$ s was generally lower in males than in females while $D$ mCO/VA5s was higher in males. This suggests that there is a sex difference both in the structure of the alveolocapillary membrane and in the capillary blood volume when normalised to VA.

Agreement between our two sets of equipment was evaluated for DLCO5s and DLNO measurements after adjustment for the known independent variables. No significant difference was found.

\section{Discussion}

The present study is one of the largest of its kind to present reference equations for the combined DLCONO measurement. In particular, the group of subjects aged $>70$ years is unparalleled in earlier studies. In addition, it is first large-scale standalone study performed on a single uniform population to present

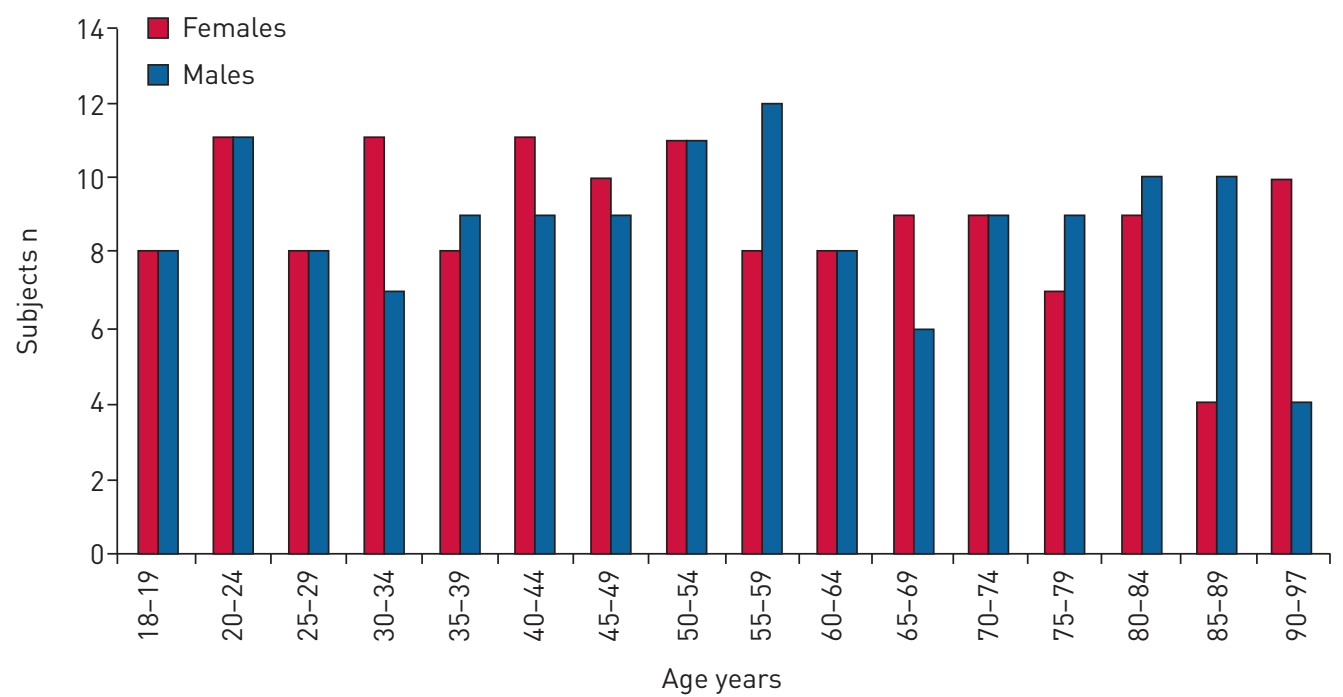

FIGURE 1 Age distribution of the study population.

TABLE 3 Reference equations for the diffusing capacity of the lung for carbon monoxide and nitric oxide

$\begin{array}{cccc}\begin{array}{c}\text { Subjects } \\ \text { after data }\end{array} & \text { Multiple linear regression equation } & \text { Adjusted } & \text { Residual } \\ \text { screening } n & & r^{2} & \begin{array}{c}\text { standard } \\ \text { error }\end{array}\end{array}$

\begin{tabular}{|c|c|c|c|c|}
\hline \multicolumn{5}{|l|}{ Females } \\
\hline$D \mathrm{LCO} 5 \mathrm{~s} \mathrm{~mL} \cdot \mathrm{min}^{-1} \cdot \mathrm{mmHg}^{-1}$ & 141 & $-3.58+0.192 \cdot$ height $-0.00166 \cdot$ age $^{2}$ & 0.766 & 2.8 \\
\hline $\mathrm{K} \operatorname{coss}^{\Upsilon} \mathrm{mL} \cdot \mathrm{min}^{-1} \cdot \mathrm{mmHg}^{-1} \cdot \mathrm{L}^{-1}$ & 140 & $6.35-0.0316$.age & 0.649 & 0.524 \\
\hline$D\left\llcorner N O \mathrm{~mL} \cdot \mathrm{min}^{-1} \cdot \mathrm{mmHg}^{-1}\right.$ & 142 & $-2.36+0.766 \cdot$ height $-0.00753 \cdot$ age $^{2}$ & 0.796 & 11.4 \\
\hline$V_{A 5 s} L$ & 141 & $-3.55+0.0466 \cdot$ height $+0.0391 \cdot$ age $-0.000426 \cdot$ age $^{2}$ & 0.534 & 0.488 \\
\hline$V_{c} \mathrm{~mL}$ & 141 & $-13.8+0.527 \cdot$ height-0.00421.age ${ }^{2}$ & 0.693 & 8.70 \\
\hline Dmco $\mathrm{mL} \cdot \mathrm{min}^{-1} \cdot \mathrm{mmHg}^{-1}$ & 142 & $3.76+0.591 \cdot$ height $-0.00620 \cdot$ age $^{2}$ & 0.744 & 10.8 \\
\hline $\mathrm{K} \operatorname{coss}^{91} \mathrm{~mL} \cdot \mathrm{min}^{-1} \cdot \mathrm{mmHg}^{-1} \cdot \mathrm{L}^{-1}$ & 139 & 7.88-0.0107-height-0.000345. $\mathrm{age}^{2}$ & 0.733 & 0.487 \\
\hline DLNO $\mathrm{mL} \cdot \mathrm{min}^{-1} \cdot \mathrm{mmHg}^{-1}$ & 138 & $5.72+0.970 \cdot$ height $-0.0125 \cdot$ age $^{2}$ & 0.824 & 16.6 \\
\hline $\mathrm{KNO}^{+} \mathrm{mL} \cdot \mathrm{min}^{-1} \cdot \mathrm{mmHg}^{-1} \cdot \mathrm{L}^{-1}$ & 139 & $38.8-0.0689 \cdot$ height$^{-0.00168 \cdot \mathrm{age}^{2}}$ & 0.777 & 2.07 \\
\hline$V_{A 5 s} L$ & 138 & $-7.90+0.0387 \cdot \mathrm{age}+0.0774 \cdot$ height $-0.000442 \cdot \mathrm{age}^{2}$ & 0.588 & 0.687 \\
\hline$V_{c} \mathrm{~mL}$ & 138 & $-23.8+0.645 \cdot$ height $-0.00547 \cdot$ age $^{2}$ & 0.767 & 9.31 \\
\hline$D \mathrm{mCO} \mathrm{mL} \cdot \mathrm{min}^{-1} \cdot \mathrm{mmHg}^{-1}$ & 138 & $50.4+0.623 \cdot$ height $-0.0123 \cdot \mathrm{age}^{2}$ & 0.743 & 19.6 \\
\hline
\end{tabular}

To obtain lower and upper limits of normal (corresponding to the 2.5th and the 97.5th percentile, respectively) subtract or add 1.96.residual standard error to the equation. DLC05s: diffusing capacity of the lung for carbon monoxide; Kco5s: diffusion capacity per unit alveolar volume for carbon monoxide; $D$ LNO: diffusing capacity of the lung for nitric oxide; $V_{A} 5$ s: alveolar volume; $V_{c}$ : capillary volume; $D$ mco =diffusing capacity

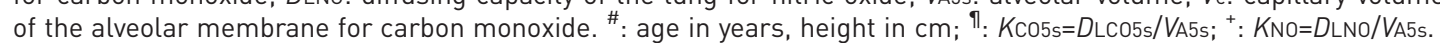


Males
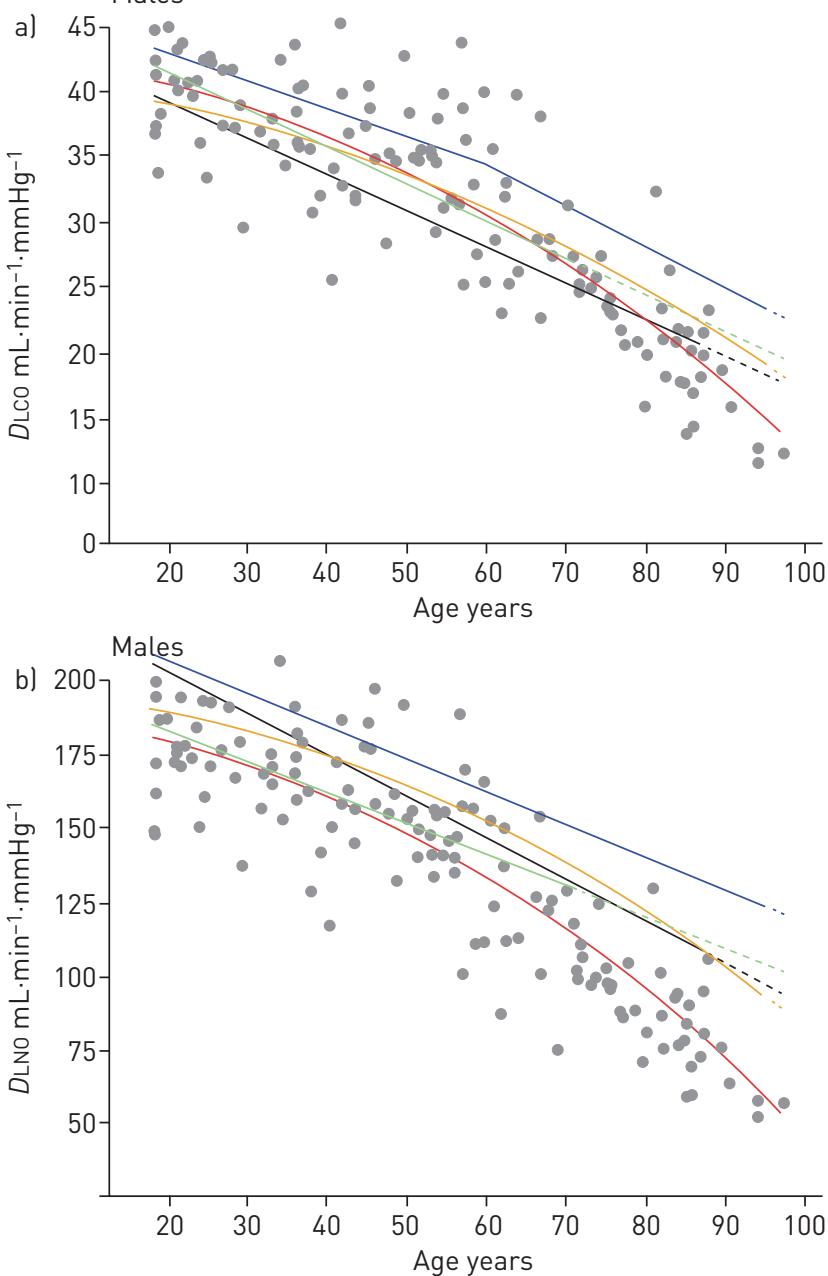

Females

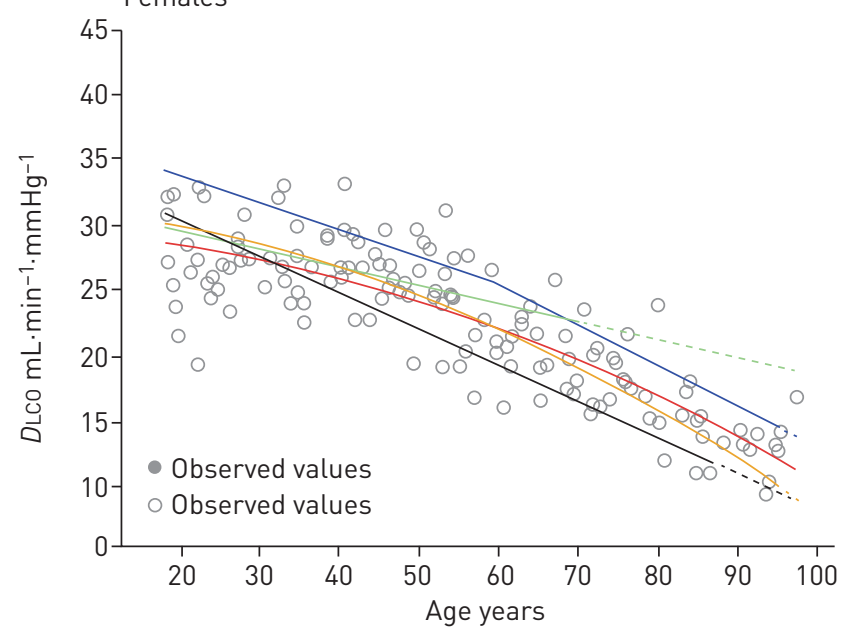

Females

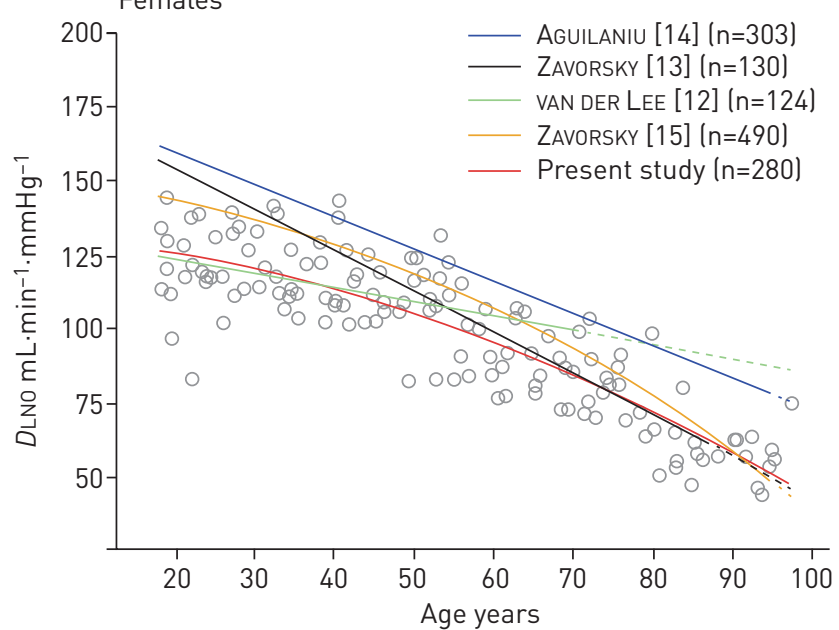

FIGURE 2 a) Diffusing capacity of the lung for carbon monoxide (DLCO) and b) nitric oxide (DLNO) compared to previously published reference equations [12-14]. For each age group, median anthropometric values from our subjects were inserted into the reference equations and the predicted values were depicted as a function of age. Dots represent values measured on each of the subjects. Breath-hold time (true apnoea period) was $5 \mathrm{~s}$ in the present study and $5 \mathrm{~s}$ in the study by ZAVORSKY et al. [13], $4 \mathrm{~s}$ in the study by AguILANIU et al. [14] and 10 $\mathrm{s}$ in the study by vaN DER LeE et al. [12].
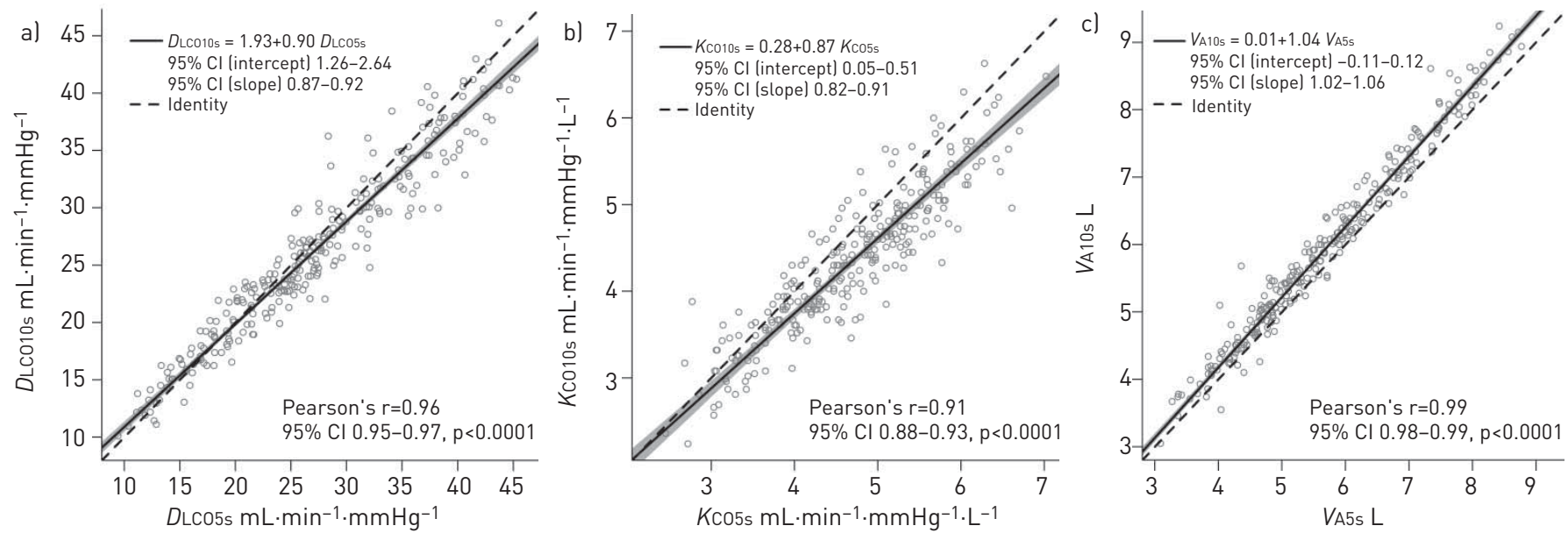

FIGURE 3 Comparison of a) diffusing capacity of the lung for carbon monoxide from the standard 10-s method (DLco10s) and from the combined method (DLCO5s); b) carbon monoxide transfer coefficient from the standard 10-s method (Kco10s) and from the combined method (Kc05s); and c) alveolar volume from the standard $10-\mathrm{s}$ method $\left(V_{A} 10 \mathrm{~s}\right)$ and from the combined method ( $V_{A 5}$ s). Passing-Bablok regressions are shown in the upper left corner of each figure. 
TABLE 4 Reference equations for capillary volume $\left(V_{c}\right) / a l v e o l a r ~ v o l u m e ~(V A 5 s)$ and diffusing capacity of the alveolar membrane for carbon monoxide $\left(D_{\mathrm{mCO}}\right) / \mathrm{VA} 5 \mathrm{~s}$

\begin{tabular}{|c|c|c|c|c|}
\hline & $\begin{array}{l}\text { Subjects after data } \\
\text { screening } n\end{array}$ & Multiple linear regression equation ${ }^{\#}$ & Adjusted $r^{2}$ & $\begin{array}{c}\text { Residual } \\
\text { standard error }\end{array}$ \\
\hline$V_{c} / V_{A 5 s} \mathrm{~mL} \cdot \mathrm{L}^{-1}$ & 279 & $15.4-0.0391 \cdot$ age $-0.972 \cdot$ sex $-0.000352 \cdot$ age $^{2}$ & 0.577 & 1.56 \\
\hline$D_{m \mathrm{mco}} / V_{\mathrm{A} 5 \mathrm{~s}} \mathrm{~mL} \cdot \mathrm{min}^{-1} \cdot \mathrm{mmHg}^{-1} \cdot \mathrm{L}^{-1}$ & 278 & 31.8-0.151-age+2.21·sex-0.0432 height & 0.678 & 2.28 \\
\hline
\end{tabular}

reference equations for $D \mathrm{mCO}$ and $V_{\mathrm{c}}$ based on a finite value of $4.5 \mathrm{mLNO} \cdot \mathrm{mLblood}^{-1} \cdot \mathrm{min}^{-1} \cdot \mathrm{mmHg}^{-1}$ for the conductance of $\mathrm{NO}(\theta \mathrm{NO})[7]$.

Furthermore, apparently we are the first to find a small but statistically significant relationship between the DLNO/DLCO ratio and age. This might be a consequence of the relatively large number of older people included in the present study. However, although it is statistically significant, it is worth noting that the change with age is minor, especially compared to the standard deviation of the values. So for clinical purposes DLNO/DLCO can be regarded as an age-independent variable with a mean value of 4.4.

As mentioned in the Methods section, $\mathrm{Hb}$ measurements were performed in all participants, but correction for $\mathrm{Hb}$ proved to have no or only minor effect on the overall results. It did not significantly change the mean of any of the main outcomes, apart from DmCO which increased slightly from 100.4 to $101.7 \mathrm{mLCO} \cdot \mathrm{min}^{-1} \cdot \mathrm{mmHg}^{-1}$. Nor did the $\mathrm{Hb}$ correction improve the adjusted $\mathrm{r}^{2}$ for any of the reference equations, and consequently only reference equations for non- $\mathrm{Hb}$ corrected values are presented. Our observations on this point are in concordance with those of STAM et al. [30] and ZAVORSKY [23], the latter finding changes in DLCO of only $\sim 3 \%$.

\section{Comparison to other reference equations}

As seen in figure 2, the reference equations of the present study estimate comparable, but for DLNO somewhat lower values, to those obtained if using one of the other reference equations for adults [12-15, 31]. As described in the Methods section, quality control of measurements was an integrated part of this study and both sets of equipment passed all tests performed. In addition, the fact that no statistically significant difference was found when comparing measurements from the two sets of equipment strengthens our belief that both measured correctly throughout the study.

Of the five reference equations compared in figure 2, AGUILANIU et al. [14] produced the highest predicted values. Several circumstances might work together to explain the difference between their results and the results from the present study. Firstly, Agullaniu et al. [14] performed their measurements at two different sites (the cities of Grenoble and Bordeaux) and reported significant effects on both DLCO and DLNO, which were lower in Grenoble than in Bordeaux (mean differences 8.5\% and 13.2\%, respectively). In figure 2 we have used their equations based on the entire population, which therefore results in higher values than if the Grenoble equations had been used. In addition, although they performed at least two acceptable tests for each subject, apparently AgUiLANiu et al. [14] used only values from the test with the greater DLCO, which differs from the ATS/ERS recommendation, according to which the mean of two acceptable measurements should be reported [20]. In the present study we used the mean of two acceptable measurements, and this difference in procedures contribute to the observed discrepancy between the studies. Other possible explanations of the observed differences might be that different equipment was used, as well as differences in the populations studied. Finally, deviations in the simultaneously measured VA might have a rather large impact on DLCO and DLNO. But as Agullaniu et al. [14] did not present information about VA, comparison with $V$ A from the present study and its potential influence on the other presented values cannot be made.

As seen in figure 2, only the predicted values from the present study, the study by AguiLANIU et al. [14] and the combined dataset by ZAVORSKY et al. [15] take into account the observed accelerated loss of diffusing capacity with age. The reason why ZAVORSKY et al. [13] and VAN DER LeE et al. [12] have only one slope, when values are fitted for age, might be that the number of old people in their studies have been too low to reliably detect this accelerated change with age. In the case of VAN DER LEE et al. [12], the slopes depicted in figure 2 are markedly less steep than those from the other studies, which is probably also an effect of the relatively young population in that study. Also notable is the rather high value of 5.1 for the DLNO/DLCO ratio found by ZaVORSKY et al. [13] (current consensus is that the ratio is in the range of 4.3-4.9 [6]; values from present study $=4.4$, van DER LeE et al. $[12]=4.5$ and Aguilaniu et al. $[14]=4.75$ ). 
If this is not a consequence of actual differences between different study populations, it can result from measures of DLNO being too high or measures of DLCO being too low or a mixture of the two. We like to think that the first possibility has had the greatest significance, since ZAvORSKY et al.'s [15] combined values for DLCO fit almost perfectly with the values from the present study. It should be mentioned that methods, equipment and of course study populations were different in all four studies discussed. In relation to differences in study population, it has been shown that differences in physical activity status have an impact on diffusion parameters [31-34]. Likewise, differences in exposure to air pollution might affect lung function. These aspects have not been analysed in the present study, but they might explain some of the observed variation between studies.

\section{DLCoNo method versus standard DLCo method}

As seen in figure 3, some differences can be observed between values obtained from the DLCONO method and the standard DLCO method.

The largest difference is in VA, with VA5s being generally lower than VA10s. In part, this difference might be a result of inadequate mixing of the inert gas with the alveolar gas since short breath-hold times have been shown to lower the measured VA in some patient groups and in healthy subjects [35-37]. Other important possible reasons for the observed difference are the differences in methodology between the two methods (see table 1). For example, the inert gas used in the calculation of VA is not the same (He versus $\mathrm{CH}_{4}$ ). The two gases might have different distributions in the lung and different solubility in tissue owing to their physical properties, and this might lead to differences in the measured VA.

KCO has been shown to increase with decreasing breath-hold time [37]. When looking at DLCO, this increase in KCO will tend to counteract the effect of a decreasing VA on DLCO. Indeed, classically DLCO is thought to increase with decreasing breath-hold time, which is shown in studies where breath-hold time is the only factor being changed (that is, same methodology in all other aspects) $[37,38]$. In the present study, KCO5s is generally larger than KCO10s, as seen in figure $3 \mathrm{~b}$. And, as described above, this increase is seen to "compensate" for the decrease in VA, thereby resulting in DLCO5s being slightly but significantly larger than DLCO10s (mean \pm SD difference $=0.85 \pm 2.3 \mathrm{~mL} \cdot \mathrm{min}^{-1} \cdot \mathrm{mmHg}{ }^{-1}$ ). In summary, as seen in table 1 the two methods differ in a number of ways, and more research is needed in order to determine how these differences in methodology influence VA, KCO and DLCO. What is certain is that DLCO measured using the two different methods cannot be used interchangeably, that is, specific reference material has to be used for each of the two methodologies.

\section{Sex difference in $\mathrm{V}_{c} / \mathrm{N}_{A}$, Dmco/NA and DLNO/DLCO5s}

Both $V_{\mathrm{c}} / V_{\mathrm{A}}$ and $D \mathrm{mCO} / V_{\mathrm{A}}$ were to some extend affected by sex, although in opposite directions: $V_{\mathrm{c}} / V_{\mathrm{A}}$ was generally slightly higher in females, while $D \mathrm{mCO} / V \mathrm{~A}$ was lower. This suggests that there is a sex difference both in the alveolocapillary membrane and in the pulmonary capillary volume when normalised to VA. However, this observed sex difference is affected by the method used for correcting for $\mathrm{Hb}$. This should be kept in mind if subsequent studies are to compare similar results with the results presented here.

In contrast, DLNO/DLCO5s showed no sex difference. However, it is important to note that the DLCO5s values used in this calculation were not corrected for $\mathrm{Hb}$. Since $\mathrm{Hb}$ is generally lower in females, the resultant values for DLCO5s should be lower for this reason alone. Therefore, if no sex difference existed between the alveolocapillary membrane and the pulmonary capillary volume when normalised to $V A$, then we would expect DLNO/DLCO5s to be higher in females than in males, which was not the case in the present study.

\section{DLNO/DLCO}

It has been pointed out that the DLNO/DLCO ratio might be the best way to assess the relationship between

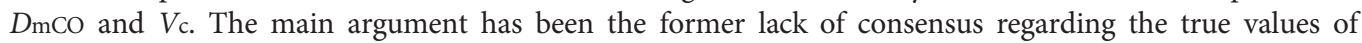
$\theta \mathrm{CO}, \theta_{\mathrm{NO}}$ and $\alpha$ used in the calculation of $D_{\mathrm{mCO}}$ and $V_{\mathrm{c}}$, since the DLNO/DLCO ratio has the advantage of being independent of these values [6]. Certainly, the ratio can tell us something about the relationship between $D$ mCO and $V_{c}$, and in the case of a low measured DLCO value it could point in the direction of the parameter ( $D$ mCO or $V_{c}$ ) predominantly accountable for the decrease. However, caution should be exercised when looking at the ratio alone, since an apparently normal value could result from both DLNO and DLCo being low, and in addition a low ratio could of course either result from a low value of DLNO or a high value of DLCO, while the opposite could apply to a high ratio. Furthermore, the scatter of the normal values for the ratio is rather large (mean \pm SD $4.4 \pm 0.24$ ), and for patients the scatter of values is also found to be large $[39,40]$. Obviously, this might result in difficulties differentiating between normal and pathological values. The usage of specific values for $D \mathrm{mCO}$ and $V_{\mathrm{c}}$ could overcome some of these challenges and in addition it could provide a more detailed view of the resistances associated with lung 
diffusion. But as mentioned, if this is to become reality, consensus has to be made regarding the calculation of $D \mathrm{mCO}$ and $V$ c. As discussed later, this might be achievable today.

\section{$\theta \mathrm{CO}, \theta$ NO and $\alpha$}

In recent years, most scientists have agreed that the most correct values for $\theta \mathrm{CO}$ are those presented by ForSTER [11] in 1987, and thereby not the 1957 values presented by ROUGHTON and ForSter [2]. Forster himself argued that these new values were more correct, particularly since they were measured at a physiological pH of 7.4 and not $\mathrm{pH} 8.0$ like the 1957 values [9, 12, 14]. In 2016, GuÉNARD et al. [41] tested several of the available $1 / \theta \mathrm{CO}$ versus $\mathrm{P}_{\mathrm{capO}}$ equations by exposing 10 normal subjects to two different inspiratory oxygen concentrations while measuring DLNO and DLCO. Several of the equations managed to keep changes in the $D \mathrm{~m} / V_{\mathrm{c}}$ ratio at a minimum during changes in $P_{\mathrm{capO}}$, among these the equation proposed by FoRSTER [11]. On the basis of these results, GUÉNARD et al. also proposed a new "best-fit" equation. This equation is used in the work by ZAVORSKY et al. [15], since they found that there is still insufficient information to decisively choose between the existing published $1 / \theta \mathrm{CO}$ versus $P_{\mathrm{capO}}$ equations derived in vitro. However, it is important to note that very little difference is seen in values for $D \mathrm{~m}$ and $V_{\mathrm{c}}$ when comparing this new equation to the equation by FORSTER. Therefore, in the present study we have decided to continue with the in vitro Forster equation.

Concerning the true value of $\alpha$, in line with most other researchers we consider the true value to be 1.97 , since this is the theoretical value representing the relationship between the physical solubilities of NO and $\mathrm{CO}$ in plasma taking into account their molecular weight $[3,25]$. Some researchers have forced $\alpha$ to higher values in order to achieve a better fit of $D \mathrm{mCO}$ and $V_{\mathrm{c}}$ values obtained from the DLCONO method with values obtained from the oxygen two-step Roughton-Forster DLCO method. For example, in this way TAmhane et al. [42] found $D \mathrm{LNO} / D \mathrm{mCO}$ (two-step) $=2.42$. An explanation for this might be that in their calculations they used $\theta \mathrm{NO}=$ infinite (thereby assuming $D \mathrm{LNO}=D \mathrm{mNO}$ ) together with the 1957 values for $\theta$ CO. If instead they had used $\theta \mathrm{NO}=$ finite, $D \mathrm{mNO}$ would not be equal to $D \mathrm{LNO}$, but would exceed this value by $\sim 70-80 \%$ (according to values from the present study and Hughes and Bates [43]). This would lead to an apparent $D \mathrm{mNO} / D \mathrm{mCO} \sim 4.1-4.3$. However, using 1987 values for $\theta$ CO increases $D \mathrm{mCO}$ approximately two-fold compared to the 1957 values, thereby leading to $\alpha$ values that might be better in concordance with the theoretical value of 1.97 [43]. In any case, since $\alpha$ is defined as the physical diffusivity ratio between $\mathrm{NO}$ and $\mathrm{CO}$, the approach by TAMHANE et al. [42] cannot be correct.

Much debate has been focused on the correct value of $\theta$ NO. In 1987, GuENARD et al. [3] assumed 1/9No to be negligible when they first introduced the single-breath DLCONO measurement as a possible means of determining $D \mathrm{mCO}$ and $V$ c. Since then, many researchers have regarded $\theta$ NO as being infinitely great with reference to the very fast reaction rate of $\mathrm{NO}$ with free $\mathrm{Hb}$. However, in recent years experiments in vitro as well as in vivo conducted by Borland and colleagues [7, 44] have consolidated the in vitro value of ӨNO=4.5 $\mathrm{mLNO} \cdot \mathrm{mLblood}^{-1} \cdot \mathrm{min}^{-1} \cdot \mathrm{mmHg}^{-1}$ first presented by CARLSEN and COMROE JR [45] in 1958. In addition, BORLAND and colleagues $[7,44]$ showed that red blood cell lysis in a membrane oxygenator model of CO and NO transfer or substitution of red blood cells with cell-free haem-based oxyglobin in anaesthetised dogs increased DLNO considerably while DLCO hardly changed. This has led researchers who previously regarded $\theta$ NO to be infinite to consider it finite with a value of $4.5 \mathrm{mLNO} \cdot \mathrm{mLblood}{ }^{-1} \cdot \mathrm{min}^{-1} \cdot \mathrm{mmHg}^{-1}[4,6,39]$.

According to the work of Roughton and Forster from 1957 [2], the red blood cell fraction of the total resistance to $\mathrm{CO}$ uptake was estimated to be $\sim 50 \%$. However, newer evidence including morphometric measurements of $\mathrm{Dm}$ and re-calculation of values obtained from the oxygen two-step Roughton-Forster DLCO method suggests that this fraction is more likely to be $\sim 75-80 \%[43,46]$. Some well-known features of DLCO argue in favour of the view that $1 /\left(\theta \mathrm{CO} \cdot V_{\mathrm{c}}\right)$ should be the most important rate-limiting factor for CO transfer: 1) anaemia, increase of carboxyhaemoglobin and/or raising of $P_{\mathrm{CapO}_{2}}$ all lower DLCO; and 2) DLCO is low in some pulmonary vascular conditions with normal vital capacity $[43,47,48]$. Values from the present study support this more current view of the distribution of resistances for CO uptake, since the average red blood cell fraction of the total resistance in our study was $72.3 \%$. In addition, the same fraction for NO uptake was $39.3 \%$, which parallels the value of $37 \%$ presented by BorLAND et al. [7].

\section{Breath-hold time}

Another area that needs to be consistent between studies using the DLCONO measurement is the breath-hold time. Standard breath-hold time for the DLCO measurement is $10 \mathrm{~s}$, but this is not suitable for the combined DLCONO measurement, since NO transfer is $\sim 4.5$ times faster than for CO. This leads to very low concentrations of $\mathrm{NO}$ after $10 \mathrm{~s}$, which is therefore undetectable by electrochemical cells. Use of a more sensitive chemiluminescent analyser circumvents this problem, but adds considerably to the expense. In the present study we chose a breath-hold time of $5 \mathrm{~s}$ (true apnoea period), which is in concordance with earlier studies $[13,14,49]$. 


\section{Caution with automated procedures}

The data presented have been obtained by using of equipment and largely automated procedures. This has some obvious advantages regarding effectiveness and ease of use. However, since we experienced more than one incident where these automated procedures did not comply with our needs and where manual correction of data therefore was needed, we would like to call attention to the fact that caution has to be taken when using such automated procedures.

\section{Clinical implications}

To date, several studies have pointed at the added value of DLCONO compared to measurement of DLCO alone when examining patients with different pulmonary disorders. This ranges from pulmonary vascular diseases such as chronic thromboembolic pulmonary hypertension to sarcoidosis and cystic fibrosis [40, 50, 51]. Unfortunately, a lack of concordance concerning the DLCONO method and computation of DmCO and $V_{c}$ complicates the interpretation and in particular, comparison of results. As proposed by HuGHES and VAN DER LEE [6], a way to circumvent some of these discrepancies is to look mainly at the ratio of DLNO/DLCO, which according to the studies mentioned shows alterations specific to different pulmonary disorders. However, being able to reliably measure $D_{\mathrm{mCO}}$ and $V_{\mathrm{c}}$ and by comparing the results between studies and with the updated reference material presented in this study, we hope that future studies will be able to provide more information on the pathoanatomy and pathophysiology of pulmonary disorders. It seems achievable to use information obtained from the DLCONO measurement in the everyday clinical work-up of patients.

\section{Conclusion}

The present study is one of the largest to date to present reference equations for the DLCONO measurement. In particular, subjects $>70$ years of age are very well represented, which is exceedingly important as an increasing number of patients are in this age group. In addition, it is the first large-scale standalone study performed on a single uniform population to present reference equations for $D$ mCO and $V_{\mathrm{c}}$ derived from the DLCONO measurement and using current state-of-the-art methodology in the computation of these two measures.

We found age, sex, height and age squared to be independent explanatory variables of the main outcomes. However, the four explanatory variables were not independent predictors of all outcomes. For all outcomes, we found an accelerated loss of capacity with age, which is represented by a negative value of the parameter for the independent variable age squared present in all the reference equations.

We believe that the DLCONO measurement and its ability to determine $D$ mCO and $V_{c}$ has great potential in future research and diagnostics of pulmonary disorders. Yet, in order to reap the full benefits of this technique, in addition to reliable reference equations, consensus concerning methods and computations must be reached. In recent years, much has changed in this field, but finally agreement seems to be within arm's reach. Therefore, we urge future studies to use this newest methodology as it is presented in this article.

Acknowledgement: We thank the bioanalytical technologist in the Department of Clinical Physiology, Nuclear Medicine and PET, Rigshospitalet (Copenhagen, Denmark), for their help in performing the lung function tests.

Conflict of interest: M. Munkholm reports grants from Danish Lung Association, Boehringer Ingelheim, GlaxoSmithKline, Novartis and Alere, and non-financial support from Intra Medic, during the conduct of the study. L. Bjerre-Kristensen reports grants from Danish Lung Association, Boehringer Ingelheim, GlaxoSmithKline, Novartis and Alere, and non-financial support from Intra Medic, during the conduct of the study. F. Madsen reports grants from Allergy and Lung Clinic Helsingør, during the conduct of the study. O.F. Pedersen reports grants from Danish Lung Association, Boehringer Ingelheim, GlaxoSmithKline, Novartis and Alere, and non-financial support from Intra Medic, during the conduct of the study. P. Lange reports grants from Danish Lung Association, Boehringer Ingelheim, GlaxoSmithKline, Novartis and Alere, and non-financial support from Intra Medic, during the conduct of the study. J. Mortensen reports grants from Danish Lung Association, Boehringer Ingelheim, GlaxoSmithKline, Novartis and Alere, and non-financial support from Intra Medic, during the conduct of the study. J.L. Marott reports grants from Danish Lung Association, Boehringer Ingelheim, GlaxoSmithKline, Novartis and Alere, and non-financial support from Intra Medic, during the conduct of the study.

Support statement: This study received financial support from Alere, Boehringer Ingheim, Danmarks Lungeforening, GlaxoSmithKline and Novartis, and nonfinancial support from Intra Medic. Funding information for this article has been deposited with the Crossref Funder Registry.

\section{References}

Krogh M. The diffusion of gases through the lungs of man. J Physiol 1915; 49: 271-300.

2 Roughton FJ, Forster RE. Relative importance of diffusion and chemical reaction rates in determining rate of exchange of gases in the human lung, with special reference to true diffusing capacity of pulmonary membrane and volume of blood in the lung capillaries. J Appl Physiol 1957; 11: 290-302. 
3 Guenard H, Varene N, Vaida P. Determination of lung capillary blood volume and membrane diffusing capacity in man by the measurements of NO and CO transfer. Respir Physiol 1987; 70: 113-120.

$4 \quad$ Zavorsky GS. No red cell resistance to NO? I think not! J Appl Physiol 2010; 108: 1027-1029.

5 Borland CD, Higenbottam TW. A simultaneous single breath measurement of pulmonary diffusing capacity with nitric oxide and carbon monoxide. Eur Respir J 1989; 2: 56-63.

6 Hughes JM, van der Lee I. The TL,NO/TL,CO ratio in pulmonary function test interpretation. Eur Respir J 2013; 41: 453-461.

7 Borland CD, Dunningham H, Bottrill F, et al. Significant blood resistance to nitric oxide transfer in the lung. J Appl Physiol 2010; 108: 1052-1060.

8 Borland C, Bottrill F, Jones A, et al. The significant blood resistance to lung nitric oxide transfer lies within the red cell. J Appl Physiol 2014; 116: 32-41.

9 Zavorsky GS, Borland C. Confusion in reporting pulmonary diffusing capacity for nitric oxide and the alveolar-capillary membrane conductance for nitric oxide. Eur J Prevent Cardiol 2015; 22: 312-313.

10 Martinot JB, Mulè M, de Bisschop C, et al. Lung membrane conductance and capillary volume derived from the NO and CO transfer in high-altitude newcomers. J Appl Physiol 2013; 115: 157-166.

11 Forster RE. Diffusion of gases across the alveolar membrane. In: Farhi LE, Tenney SM, eds. Handbook of Physiology. Washington, DC, American Physiological Society, 1987; pp. 71-88.

12 van der Lee I, Zanen P, Stigter N, et al. Diffusing capacity for nitric oxide: reference values and dependence on alveolar volume. Respir Med 2007; 101: 1579-1584.

13 Zavorsky GS, Cao J, Murias JM. Reference values of pulmonary diffusing capacity for nitric oxide in an adult population. Nitric Oxide 2008; 18: 70-79.

14 Aguilaniu B, Maitre J, Glénet S, et al. European reference equations for CO and NO lung transfer. Eur Respir J 2008; 31: 1091-1097.

15 Zavorsky GS, Hsia CC, Hughes JM, et al. Standardisation and application of the single-breath determination of nitric oxide uptake in the lung. Eur Respir J 2017; 49: 1600962.

16 Thomsen M, Nordestgaard BG, Vestbo J, et al. Characteristics and outcomes of chronic obstructive pulmonary disease in never smokers in Denmark: a prospective population study. Lancet Respir Med 2013; 1: 543-550.

17 Lawlor DA, Harbord RM, Tybjaerg-Hansen A, et al. Using genetic loci to understand the relationship between adiposity and psychological distress: a Mendelian randomization study in the Copenhagen General Population Study of 53,221 adults. J Intern Med 2011; 269: 525-537.

18 Evron S, Tress V, Ezri T, et al. The importance of blood sampling site for determination of hemoglobin and biochemistry values in major abdominal and orthopedic surgery. J Clin Anesthes 2007; 19: 92-96.

19 Jones RS, Meade F. A theoretical and experimental analysis of anomalies in the estimation of pulmonary diffusing capacity by the single breath method. Q J Exp Physiol Cogn Med Sci 1961; 46: 131-143.

20 Macintyre N, Crapo RO, Viegi G, et al. Standardisation of the single-breath determination of carbon monoxide uptake in the lung. Eur Respir J 2005; 26: 720-735.

21 Iwamoto J, Pendergast DR, Suzuki H, et al. Effect of graded exercise on nitric oxide in expired air in humans. Respir Physiol 1994; 97: 333-345.

22 Pietropaoli AP, Perillo IB, Torres A, et al. Simultaneous measurement of nitric oxide production by conducting and alveolar airways of humans. J Appl Physiol 1999; 87: 1532-1542.

23 Zavorsky GS. The rise in carboxyhemoglobin from repeated pulmonary diffusing capacity tests. Respir Physiol Neurobiol 2013; 186: 103-108.

24 Jensen R, Leyk M, Crapo R, et al. Quality control of DL,Coinstruments in global clinical trials. Eur Respir J 2009; 33: 828-834.

25 Wilhelm E, Battino R, Wilcock RJ. Low-pressure solubility of gases in liquid water. Chem Rev 1977; 77: 219-262.

26 Løkke A, Marott JL, Mortensen J, et al. New Danish reference values for spirometry. Clin Respir J 2013; 7: 153-167.

27 Frans A, Nemery B, Veriter C, et al. Effect of alveolar volume on the interpretation of single breath DLCO. Respir Med 1997; 91: 263-273.

28 Cotes JE, Chinn DJ, Quanjer PH, et al. Standardization of the measurement of transfer factor (diffusing capacity). Report Working Party Standardization of Lung Function Tests, European Community for Steel and Coal. Official Statement of the European Respiratory Society. Eur Respir J Suppl 1993; 6: Suppl. 16, 41-52.

29 Quanjer PH, Tammeling GJ, Cotes JE, et al. Lung volumes and forced ventilatory flows. Report Working Party Standardization of Lung Function Tests, European Community for Steel and Coal. Official Statement of the European Respiratory Society. Eur Respir J 1993; 6: Suppl. 16, 5-40.

30 Stam H, Hrachovina V, Stijnen T, et al. Diffusing capacity dependent on lung volume and age in normal subjects. J Appl Physiol 1994; 76: 2356-2363.

31 Zavorsky GS, Smoliga JM. The association between cardiorespiratory fitness and pulmonary diffusing capacity. Respir Physiol Neurobiol 2017; 241: 28-35.

32 Glénet SN, de Bisschop CM, Dridi R, et al. Membrane conductance in trained and untrained subjects using either steady state or single breath measurements of NO transfer. Nitric Oxide 2006; 15: 199-208.

33 Zavorsky GS, Wilson B, Harris JK, et al. Pulmonary diffusion and aerobic capacity: is there a relation? Does obesity matter? Acta Physiol 2010; 198: 499-507.

34 Lavin KM, Straub AM, Uhranowsky KA, et al. Alveolar-membrane diffusing capacity limits performance in Boston marathon qualifiers. PLoS One 2012; 7: e44513.

35 Chang HK, Cheng RT, Farhi LE. A model study of gas diffusion in alveolar sacs. Respir Physiol 1973; 18: 386-397.

36 Graham BL, Mink JT, Cotton DJ. Effect of breath-hold time on DLCO(SB) in patients with airway obstruction. J Appl Physiol 1985; 58: 1319-1325.

37 Dressel H, Filser L, Fischer R, et al. Lung diffusing capacity for nitric oxide and carbon monoxide: dependence on breath-hold time. Chest 2008; 133: 1149-1154.

38 Blakemore WS, Forster RE, Morton JW, et al. A standardized breath holding technique for the clinical measurement of the diffusing capacity of the lung for carbon monoxide. J Clin Invest 1957; 36: 1-17.

39 Martinot JB, Guénard HJ. TLNo/TLCO ratio is not the end of the road. Eur Respir J 2014; 43: 1535-1536.

40 van der Lee I, Zanen P, Grutters JC, et al. Diffusing capacity for nitric oxide and carbon monoxide in patients with diffuse parenchymal lung disease and pulmonary arterial hypertension. Chest 2006; 129: 378-383. 
41 Guénard HJ, Martinot JB, Martin S, et al. In vivo estimates of NO and CO conductance for haemoglobin and for lung transfer in humans. Respir Physiol Neurobiol 2016; 228: 1-8.

42 Tamhane RM, Johnson RL Jr, Hsia CC. Pulmonary membrane diffusing capacity and capillary blood volume measured during exercise from nitric oxide uptake. Chest 2001; 120: 1850-1856.

43 Hughes JM, Bates DV. Historical review: the carbon monoxide diffusing capacity (DLCO) and its membrane $(D \mathrm{~m})$ and red cell $\left(\theta \cdot V_{\mathrm{c}}\right)$ components. Respir Physiol Neurobiol 2003; 138: 115-142.

44 Borland C, Dunningham H, Bottrill F, et al. Can a membrane oxygenator be a model for lung NO and CO transfer? J Appl Physiol 2006; 100: 1527-1538.

45 Carlsen E, Comroe JH Jr. The rate of uptake of carbon monoxide and of nitric oxide by normal human erythrocytes and experimentally produced spherocytes. J Gen Physiol 1958; 42: 83-107.

46 Weibel ER, Federspiel WJ, Fryder-Doffey F, et al. Morphometric model for pulmonary diffusing capacity. I. Membrane diffusing capacity. Respir Physiol 1993; 93: 125-149.

47 Gehr P, Bachofen M, Weibel ER. The normal human lung: ultrastructure and morphometric estimation of diffusion capacity. Respir Physiol 1978; 32: 121-140.

48 Hsia CC, McBrayer DG, Ramanathan M. Reference values of pulmonary diffusing capacity during exercise by a rebreathing technique. Am J Respir Crit Care Med 1995; 152: 658-665.

49 Thomas A, Hanel B, Marott JL, et al. The single-breath diffusing capacity of CO and NO in healthy children of European descent. PLoS One 2014; 9: el13177.

50 Wheatley CM, Foxx-Lupo WT, Cassuto NA, et al. Impaired lung diffusing capacity for nitric oxide and alveolar-capillary membrane conductance results in oxygen desaturation during exercise in patients with cystic fibrosis. J Cyst Fibros 2011; 10: 45-53.

51 Phansalkar AR, Hanson CM, Shakir AR, et al. Nitric oxide diffusing capacity and alveolar microvascular recruitment in sarcoidosis. Am J Respir Crit Care Med 2004; 169: 1034-1040. 